\title{
PUBLISH OR PERISH
}

$\mathrm{O}^{\mathrm{N}}$ p. 724 of this issue of Nature appear a few comments by Sir Lindor Brown, a secretary of the Royal Society of London and chairman of that Society's Committee on Scientific Information, concerning publication of proceedings of conferences and symposia. We would strongly urge all scientists and publishers to read and ponder them, for they have long needed making. Meetings, on both the national and international scale, have been held from time to time which dealt with this very subject---publication, documentation, retrieval, etc., of scientific information-and much has been said in relation to that so clearly set out by Sir Lindor Brown. But, alas, so far scientists and others seem to have contributed little more than lip service towards the solution of this universal problem; and so the avalanche of scientific literature--books, journals, preprints, reprints, etc.continues to gain in mass and momentum.

Sir Lindor has certainly practised considerable economy of words in a terse, yet all-important, statement: this alone many scientists might well emulate. Every sentence Sir Lindor has written is worth reading and weighing, for then one will recognize that there is as much in what Sir Lindor implies as in what he actually says. Some readers might then, to the possible advantage of all, pause and ask: "Is it I ?"

Sir Lindor has presented a case which an editor himself might find somewhat embarrassing to put forward. Nevertheless, the editor of any journal, especially one concemed with the presentation of science, often is like many an onlooker: he sees most of the game. It is true, all too true, that too much material is now being rushed into print. Sir Lindor Brown confines himself to publication of proceedings of scientific meetings; so at this point let us do the same. An overwhelming number of books reach Nature office for review (six times more than can be effectively dealt with), many of them being detailed reports of meetings, both national and international. Some are literally verbatim reports which read like the proverbial parish magazine (probably having originally been taken on a tape recorder) and which only the armchair or retired scientist could hope to find time to read. Many volumes are obviously badly edited, if edited at all. This is not good for the advancement of science or the reputation of the scientist. Then there are some published reports of proceedings which have such a comprehensive author index that the editor is faced with the problem of finding a reviewer of satisfactory erudition and/or judgment. Frequently the editor can think of a dozen or more authorities on the subject, one of whom might be invited to review the book; but he is eventually driven elsewhere, because every one he has chosen has been a contributor to the proceedings and so eventually becomes part-author of the ensuing book, which precludes him from reviewing it.
While the scientists (especially the academic scientists) persist, as many of them do, in judging a man's scientific, management and orgenizing potentialities or capabilities mainly by the volume of his publications, the problem so suecinctly emphasized by Sir Lindor Brown will still have to be faced.

At the distal end, there are the possible (if not probable) readers and buyers of such books. The former cannot hope to keep up with such a volume of literature, much of which, in any event, is of doubtful value: the latter, and especially the librarians, must find it becoming more and more difficult to separate the wheat from the chaff-something they are forced to do in view of their slender purses and overcrowded shelves.

Scientists are submitted to pressure to publish from various sources, not least persistent of which are certain publishers. It would seem more desirable that pressure should be substituted by encouragement (or, sometimes even, discouragement), and this should be offered mainly from within the fold of scientists themselves.

The solution of the problem rests with the scientists and their organizations. It is not only wrong that any scientist should be given leave by an organization or financial assistance by some authority in order to attend a conference on condition that he reads a paper at it; but it is also deplorable that a scientist should depend so much on his published works for his own professional advancement. This all tends towards rushing into print, writing of verbose articles and papers, claims for priority sometimes followed by voluminous and even acrimonious argument, little of which adds to the advancement, much less the dignity, of science itself.

Again, perhaps Nature could with advantage support, if only obliquely, Sir Lindor Brown's statement by recording what has recently occurred. By far the majority of authors of articles and letters in Nature order reprints. These are not dealt with by either editor or publisher but very efficiently by the printer. It is obvious that the last-named has to produce many thousands of these reprints each week. Alas, among the scientists, like other members of the community, we have the impatient ones. Consequently, either the editor or the printer receives inquiries from some authors who think there has been undue delay in the fulfilment of their reprint orders. Recently one author telephoned such a query (quite a common present-day practice), and, in order to save time, he was asked in which issue of Nature his article had appeared. He replied: "I don't know, I never have time to look at Nature; but so long as I know it has been published that is all that really matters". A sobering thought for publisher, printer and editor.

Publish or perish! 